\title{
Preterm premature rupture of membranes
}

\author{
César H. Meller, M.D. ${ }^{a}$, María E. Carducci, M.D. ${ }^{a}$, José M. Ceriani Cernadas, M.D. ${ }^{b}$ \\ and Lucas Otaño, M.D., Ph.D. ${ }^{a}$
}

a. Department of Obstetrics.

b. Division of Neonatology. Hospital ltaliano de Buenos Aires.

E-mail address:

César H. Meller, M.D.: cesar.meller@

hospitalitaliano.org.ar

Funding:

None.

Conflict of interest:

None.

Received: 11-16-2017 Accepted: 12-4-2017

\begin{abstract}
Preterm premature rupture of membranes occurs in around 3\% of pregnancies, and several aspects related to its management are still controversial. The objective of this update is to provide a detailed review of strategies aimed at reducing morbidity and mortality associated with this maternal condition. We will discuss the available evidence regarding the maternal use of antibiotics, the use of corticosteroids according to gestational age, the use of magnesium sulphate for fetal neuroprotection, the use of tocolytic agents, and the best moment for and route of delivery. This review also covers the effects of prolonged preterm premature rupture of membranes, infant morbidity and mortality in the short and long term, the harmful effects of antibiotics after delivery, including the effects on neurodevelopment and the presence of longterm chronic diseases.

Key words: premature rupture of membranes, preterm, antibiotics, morbidity, pregnancy, and newborn infant.
\end{abstract}

http:/ / dx.doi.org/10.5546/ aap.2018.eng.e575

To cite: Meller CH, Carducci ME, Ceriani Cernadas JM, Otaño L. Preterm premature rupture of membranes. Arch Argent Pediatr 2018;116(4):e575-e581.

\section{INTRODUCTION}

Preterm premature rupture of

amniotic fluid levels, the diagnostic suspicion is even more relevant. However, a normal amniotic fluid volume does not rule out the diagnosis.

Vaginal examination is not recommended because it increases the risk for infection and reduces the latent period to birth. ${ }^{1}$

Once PPROM is diagnosed, the patient is examined to determine if there is any indication for delivery, such as chorioamnionitis. Then, if expectant management is decided upon, interventions will be implemented.

\section{Antibiotic therapy}

Its objective is to prevent an ascending infection and prolong pregnancy so as to indicate corticosteroids and reduce perinatal and maternal morbidity. According to the Cochrane Review, the use of antibiotics versus placebo did not show significant differences in terms of neonatal mortality rate, but it did in relation to the following: $:, 5$

1. A lower incidence of chorioamnionitis; RR: $0.62(95 \%$ confidence interval [CI]: 0.51-0.75). membranes (PPROM) means the rupture of the membranes before labor starts prior to 37 weeks of gestation. The etiology of PPROM is unknown but some factors increase the risk for it, such as cervical shortening or intraamniotic infection. ${ }^{1}$

\section{DIAGNOSIS}

More than $90 \%$ of cases are confirmed based on the patient's description and a speculoscopy with monitoring of direct amniotic fluid leaking. Detection rises to $97 \%$ with the help of a nitrazine test $(\mathrm{pH}$ indicator) or a crystallography., ${ }^{2,3}$ If an ultrasound shows absent or low
2. A lower incidence of maternal infection; RR: 0.85 (95\% CI: 0.760.96).

3. An increase in the latent period to birth of $48 \mathrm{~h}$; RR: 0.77 (95\% CI: 0.72-0.83).

4. An increase in the latent period to birth of 7 days; RR: 0.88 (95\% CI: 0.84-0.92).

5. A lower incidence of neonatal infection; RR: 0.67 (95\% CI: 0.520.85).

6. A lower surfactant requirement; RR: 0.83 (95\% CI: 0.72-0.96).

7. A lower number of neonatal ultrasound lesions; RR: 0.82 (95\% CI: 0.68-0.99). 
The adequate antibiotics include: ${ }^{6-7}$

- Erythromycin (250 mg every $6 \mathrm{~h}$ orally) over 10 days. ${ }^{8,9}$

- Ampicillin (2 g every $6 \mathrm{~h})+$ erythromycin (250 mg every $6 \mathrm{~h}$ intravenously) over $48 \mathrm{~h}$ and continue with amoxicillin ( $250 \mathrm{mg}$ every $8 \mathrm{~h})+$ erythromycin (333 mg every 8 h orally) over 5 days. ${ }^{9}$

- Ampicillin (2 g every $6 \mathrm{~h})+$ erythromycin (500 mg every $6 \mathrm{~h}$ intravenously) over $48 \mathrm{~h}$ and continue with ampicillin (500 mg every $6 \mathrm{~h})+$ erythromycin (500 mg every 8 h) orally over 5 days. ${ }^{10}$

- In case of allergy or beta-lactam antibiotic resistance, clindamycin (900 mg every $8 \mathrm{~h}$ intravenously) over $48 \mathrm{~h}$ and then $300 \mathrm{mg}$ every 8 h orally over 5 days. ${ }^{11}$

Amoxicillin/ clavulanic acid is contraindicated because it increases the risk for necrotizing enterocolitis..$^{9,12}$

In relation to beta-hemolytic Streptococcus, a vaginal swab is recommended once a patient with PPROM is admitted. ${ }^{1,9}$ If it was not done or the result is not available upon delivery, antibiotic prophylaxis with penicillin or ampicillin should be given or, in the case of allergy, with clindamycin. ${ }^{3,12}$ Penicillin prevents ampicillinresistant Escherichia coli, which is a high-risk strain for newborn infants (NBIs) because it increases early sepsis. ${ }^{13}$

\section{Corticosteroids}

The recommendations in the case of PPROM are similar to those for patients at a high risk for preterm birth in general, although the following controversial issues still exist: ${ }^{14}$

\section{Preferred regimen?}

The Cochrane Reviews from 2013 and 2017 concluded that the most beneficial regimen is yet to be defined: ${ }^{15-19}$

- Betamethasone: 2 doses of $12 \mathrm{mg}$ intramuscularly $24 \mathrm{~h}$ apart.

- Dexamethasone: 4 doses of $6 \mathrm{mg}$ intramuscularly $12 \mathrm{~h}$ apart.

\section{Single or repeated doses?}

Since the effect of corticosteroids decreases if the interval to birth is more than 7 days, ${ }^{15,20}$ several studies analyzed the effects of repeated doses. ${ }^{21-27} \mathrm{~A}$ limitation of this is the heterogeneity of studies and their outcomes. Some studies found beneficial effects with repeated courses; others described untoward effects, such as a lower birth weight, height or head circumference, or a greater -but not significant- risk for cerebral palsy. ${ }^{23}$ The Cochrane Reviews from $2015,{ }^{28}$ which focused on repeated corticosteroid dose analysis, and from 2017, which carried out an overall analysis of corticosteroid use, ${ }^{19}$ concluded that further studies are necessary to define the longterm risk and benefits for the mother and the NBI and proposed a meta-analysis of individual patient data; the results of this have not been published yet. ${ }^{20,29}$

The Royal College of Obstetricians and Gynaecologists ${ }^{15}$, the American College of Obstetricians and Gynecologists, ${ }^{16,30}$ and the National Ministry of Health of Argentina ${ }^{17}$ do not recommend multiple courses of corticosteroids $(>2)$. According to the Australian Preterm Labour Clinical Guideline (2015), ' a "rescue" dose may be indicated if more than 1 week has elapsed since the first corticosteroid course and gestational age is $<32^{+6}$ weeks:

- A complete course (e.g., 2 doses of betamethasone), or

- 1 dose and, in the case of another week elapsed before birth prior to $32^{+6}$ weeks of gestation, 1 last dose.

The American College's guideline (2017) extends the "rescue" dose up to 34 weeks of gestation for pregnancies at risk for preterm birth, but it states there is no evidence for or against it in the case of PPROM. ${ }^{30}$

\section{Less than 24 weeks of gestation?}

Some studies suggested that corticosteroids as of 23 weeks of gestation may be beneficial, ${ }^{32}$ and some guidelines have already added the recommendation as of 23 weeks. ${ }^{1,30-33}$

\section{Late preterm birth?}

NBIs born between 34 and $36^{+6}$ weeks account for $70 \%$ of preterm births. A randomized clinical trial $^{34}$ compared corticosteroids versus placebo in women with singleton pregnancies between 34 and $36+{ }^{5}$ weeks of gestation at risk for preterm birth (approximately 20\% corresponded to PPROM) and found a reduction in the primary outcome measure compared to placebo (RR: 0.80, 95\% CI: 0.66-0.97). ${ }^{34}$ Hypoglycemia was more common in the betamethasone group (RR: 1.61, 95\% CI: 1.38-1.88), but there were no associated adverse events. Although some guidelines have already introduced the use of corticosteroids for late preterms, ${ }^{30}$ there is consensus that these infants require long-term follow-up. The 
frequency of neurodevelopmental disorders in this group is higher than among NBIs born at 39-41 weeks of gestation, and corticosteroids may also be beneficial at this level. ${ }^{35,36}$

\section{Multiple pregnancies?}

Most studies were conducted in singleton pregnancies; for this reason, the Cochrane Review from 2017 concluded that further studies in multiple pregnancies are required. ${ }^{19}$ Still, the guidelines recommend corticosteroid use in twin pregnancies at risk for preterm birth between $23 / 24$ and 34 weeks of gestation. ${ }^{30}$

\section{Summary of corticosteroid use in preterm premature rupture of membranes}

- A corticosteroid course should be indicated between 23/24 and 34 weeks of gestation, regardless of the number of fetuses.

- A corticosteroid course should be indicated between 34 and $36^{+6}$ weeks of gestation in singleton pregnancies.

- It should be noted that multiple courses of corticosteroids $(>2)$ are not recommended.

\section{Magnesium sulphate for fetal neuroprotection}

The survival of preterm NBIs has increased thanks to the advances in neonatal care, in association with a parallel increase in the prevalence of neurological and developmental disorders. ${ }^{37-38}$ The Cochrane Review ${ }^{37}$ on neuroprotection with magnesium sulphate showed the following outcomes:

- Cerebral palsy: relative reduction of $32 \%$; RR: 0.68 (95\% CI: 0.54-0.87).

- Gross motor dysfunction: significant reduction; RR: 0.61 (95\% CI: 0.44-0.85).

In the 6-year follow-up of the Australasian Collaborative Trial of Magnesium-Sulphate $\left(\mathrm{ACTOMgSO}_{4}\right),{ }^{39}$ no differences were found between those who received magnesium sulphate and those who did not. ${ }^{40}$ Similar results were observed in the long-term follow-up of the Prevention of cerebral palsy by magnesium sulphate (PREMAG) trial. ${ }^{41}$ However, it is still unknown whether the absence of long-term benefits is the consequence of incomplete patient follow-up, which decreases the power of the study, and the fact that cognitive development is affected by environmental factors that cannot be measured ${ }^{40}$ In addition, neither of these 2 studies found evidence of damage in the longterm follow-up, suggesting that the beneficial effects at two years would not be counteracted by subsequent damaging effects. ${ }^{42}$

In brief, the use of magnesium sulphate for fetal neuroprotection in case of imminent preterm birth prior to 32 weeks of gestation, both for singleton and multiple pregnancies, may reduce the risk for cerebral palsy and gross motor dysfunction in the short term by $30-40 \% .^{43}$

\section{Tocolytic agents}

Their use is controversial. ${ }^{44}$ It may be associated with an increased risk for chorioamnionitis without showing neonatal or maternal benefits. ${ }^{1}$ Therefore, prophylactic tocolysis should only be considered if it is necessary to prolong the pregnancy for 24-48 $\mathrm{h}$ to allow for fetal lung maturation and transfer to a facility with a higher level of care for pregnant women with $<34$ weeks of gestation. ${ }^{44-46}$

The therapeutic use of tocolytic agents among patients in labor did not show an increase in the latent period or improved neonatal outcomes. ${ }^{1}$

\section{Best moment for delivery}

The traditional recommendation is delivery at 34 weeks of gestation. ${ }^{1,10,47}$ However, this is controversial. The Cochrane Review from $2017^{48}$ compared early birth and expectant management up to 37 weeks of gestation among women with PPROM between 34 and 37 weeks.

No differences were observed in terms of neonatal sepsis (RR: $0.93,95 \%$ CI: $0.66-1.30$ ) or neonatal infection confirmed with a positive culture (RR: $1.24,95 \%$ CI: 0.70-2.21), perinatal mortality (RR: 1.76, 95\% CI: 0.89-3.50) or stillbirth (RR: $0.45,95 \%$ CI: 0.13-1.57). The following was observed in the immediate birth group:

- A higher incidence of respiratory distress (RR: 1.26, 95\% CI: 1.05-1.53).

- A higher rate of C-sections (RR: 1.26, 95\% CI: 1.11-1.44).

- A higher rate of neonatal mortality (RR: 2.55, 95\% CI: 1.17-5.56), need for mechanical ventilation (RR: $1.27,95 \%$ CI: 1.02-1.58), and admission to the intensive care unit (RR: 1.16, 95\% CI: 1.08-1.24).

Against the expectant management approach, results only showed that early birth was associated with a lower rate of chorioamnionitis (RR: 0.50, 95\% CI: 0.26-0.95).

Therefore, and although current guidelines suggest delivery at 34 weeks, an expectant management up to 37 weeks of gestation may be considered provided that there are no contraindications to continuing with the 
pregnancy and with an adequate monitoring of maternal and fetal health.

\section{Route of delivery}

PPROM by itself is not an indication for C-section.

\section{Previability}

PROM prior to 23-24 weeks of gestation, an uncommon complication, is a dilemma for both patients and physicians, and there is no consensus on its management and treatment. ${ }^{49}$ Perinatal survival has increased thanks to the advances in neonatal care. However, previable PPROM is a condition that entails a guarded prognosis and feared complications, such as early sepsis, pulmonary hypoplasia, intraventricular hemorrhage, periventricular leukomalacia, necrotizing enterocolitis, retinopathy of prematurity, and neurodevelopmental disorders. Therefore, in clinical practice, the greatest challenge is to achieve "intact" survival (without major disabilities).

A recent study ${ }^{50}$ analyzed the results of 73 pregnancies and 93 fetuses with PPROM between 15 and 23.5 weeks of gestation. Two thirds decided to continue with the pregnancy. No case of sepsis or thrombosis was observed. Eleven cases of fever with suspected endometritis that were resolved with antibiotics were reported. Among the women who continued with the pregnancy, two thirds had a live birth at a median gestational age of 22.4 weeks at the time of delivery (range: 16.2-34) and a latent period to birth of 38 days. Among live births, 20\% died in the neonatal period and $80 \%$ were discharged from the hospital. The main neonatal complications included respiratory distress syndrome $(100 \%)$, pulmonary hypoplasia $(29.5 \%)$, and infection $(56.8 \%)$. The rate of intact survival was $45.5 \%$. Thus, an expectant management is a valid option to be considered during counseling. ${ }^{1,30-33}$

\section{Considerations for future pregnancies}

Patients with singleton pregnancies and a history of prior preterm birth (with or without PPROM) should be offered an intervention to reduce the risk of recurrence; progesterone is the most commonly used drug in these cases. ${ }^{51,52}$

\section{Short- and long-term impact of preterm premature rupture of membranes in preterm newborn infants}

Most unfavorable situations affecting pregnant women, such as PPROM, have negative consequences on the fetus and the infant, very especially on extremely preterm or very low birth weight NBIs.

\section{Actions before and after childbirth}

In the presence of PPROM, an early consultation between the neonatologist and the parents is the right action. Parents usually feel very anxious and it is an ethical mandate for neonatologists to meet with them as many times as necessary. Any information given to parents should be communicated in a clear, calm manner without euphemisms, giving them time to ask questions and making them feel they are not alone.

If health care providers decide to terminate the pregnancy, parents should know the reason for such decision.

\section{Considerations in relation to neonatal clinical course}

Contrary to what might be assumed, bacterial infections are not the major problem associated with PROM, but prematurity is. However, even though infections are not very common, they account for a potentially severe condition occurring before birth due to the ascending bacteria from the vagina. Their incidence depends mostly on maternal clinical care and the presence of chorioamnionitis. Strict monitoring techniques, especially avoiding vaginal examination, reduce the likelihood of maternal and fetal infections. In our experience, around 3\% of preterm births with PROM had confirmed sepsis, but there is consensus that the rate of infection is twice as high among preterm infants born at less than 28 weeks of gestation. ${ }^{53}$

\section{Care before and after childbirth}

Initial care is that usually provided when delivering high-risk NBIs and, if necessary, the current standards of neonatal resuscitation should be implemented. Actions at the neonatal care unit are also similar and, depending on the clinical presentation, necessary treatments and tests will be established.

Preterm infants born to mothers with PROM should be frequently monitored but this does not mean that those born after 35 weeks of gestation and without symptoms should not be monitored in the room with their mothers.

Ancillary tests to detect infections are necessary in NBIs with clinical signs of sepsis 
and in extremely preterm infants. The widespread practice of performing lab tests and cultures in all infants born to mothers with PROM is unfounded.

\section{Considerations on the maternal use of antibiotics}

In recent years, potential harmful effects have been observed in NBIs whose mothers received certain antibiotics. Intrauterine colonization has an important impact on the development of immunity and metabolism in NBIs. Microbiota alteration before and / or after birth, associated with epigenetic modifications, may lead to diseases in the neonatal and later periods..$^{54,55}$ However, a study found that the indication of erythromycin in mothers was not associated with learning deficits at 11 years old, another reason for this to be the antibiotic of choice. ${ }^{56}$

\section{Antibiotics in preterm newborn infants}

The indication of antibiotics has been highly controversial because of the potential shortand long-term harmful effects. This practice is usually implemented in most preterm infants born to mothers with PROM, even in the absence of clinical signs, which is inadequate because it may be associated with certain risks, such as gut flora alteration, which leads to greater morbidity both in the neonatal period and in the long term. ${ }^{57,58}$ Not with standing this, owing to the usual respiratory disorders and hemodynamic alterations observed in preterm infants, together with the presence of PROM, it is very difficult to define the presence or absence of early sepsis, which may warrant the administration of antibiotics in special situations. In the case of chorioamnionitis, preterm infants usually receive antibiotics since the moment of birth, even if they have no clinical signs. This is a very debatable action which lacks evidence-based support and that is based on the likelihood of a subclinical infection at birth, which is highly improbable. ${ }^{58-61}$ However, a serious problem is that, in many neonatal care units, antibiotics are indicated to NBIs without maternal infection or clinical symptoms, just based on the history of PROM. This is an entirely inadequate practice because it increases damages by altering the gut microbiota and causes other short- and long-term harmful effects. Such improper action increases the presence of late sepsis, the most common cause of death in neonatal care units, and its long-term consequences may lead to neurodevelopmental disorders ${ }^{62,63}$ and greater bacterial resistance. ${ }^{64}$

In addition, several studies observed that antibiotic use in NBIs was associated with chronic gastrointestinal diseases in adolescents and adults, such as inflammatory bowel disease ${ }^{65,66}$ and Crohn's disease, ${ }^{67}$ both associated with a higher risk for abdominal cancer. ${ }^{68}$

To conclude, it is critical for neonatologists to avoid the unwarranted use of antibiotics due to the very high risk for severe adverse reactions in the neonatal period and in the long term. ${ }^{69,70}$

\section{REFERENCES}

1. American College of Obstetricians and Gynecologists' Committee on Practice Bulletins-Obstetrics. Practice Bulletin No. 172: Premature Rupture of Membranes. Obstet Gynecol 2016; 128(4):e165-77.

2. Royal College of Obstetricians and Gynaecologists. Preterm Prelabour Rupture of Membranes. Green-Top Guideline 2006;44. [Accessed on: December 5th, 2017]. Available at: https: / / www.ranzcog.edu.au/RANZCOG_SITE/ media / RANZCOG-MEDIA / Women $\% 27 \mathrm{~s} \% 20$ Health / Statement\%20and\%20guidelines / Clinical-Obstetrics / RCOG-Preterm-Prelabour-Rupture-of-Membranes. pdf?ext=.pdf.

3. Mercer BM. Preterm premature rupture of the membranes. Obstet Gynecol 2003; 101(1):178-93.

4. Kenyon S, Boulvain M, Neilson J. Antibióticos para la rotura prematura de membranas (translated Cochrane Review). La Biblioteca Cochrane Plus. 2007;4. [Accessed on: December 5th, 2017]. Available at: http:/ / www.maternoinfantil.org/ archivos / A51.PDF.

5. Mercer BM, Artheart Kl. Antimicrobial therapy in expectant management of preterm premature rupture of the membranes. Lancet 1995; 346(8985):1271-9.

6. Greenberg R, Hankins G. Antibiotic Therapy in Preterm Premature Rupture of Membranes. Clin Obstet Gynecol 1991; 34(4):742-50.

7. Susacasa S. Consenso SOGIBA 2017: Rotura prematura de Membranas en el embarazo de pretérmino (RPMp). [Accessed on: December 5th, 2017]. Available at: http: / / www.sogiba.org.ar/images / RPMP_Consenso_ SOGIBA_2017.pdf.

8. NICE Guideline. Preterm labour and birth. November 2015. [Accessed on: December 5th, 2017]. Available at: https:/ / www.nice.org.uk/guidance/ng25/ resources / pretermlabour-and-birth-pdf-1837333576645.

9. Yudin MH, vanSchalkwykJ, Van Eyk N. Antibiotic therapy in preterm premature rupture of the membranes. J Obstet Gynaecol Can 2017;39(9):e207-12.

10. Di Marco I, Asprea I, Cuetos M, et al. Recomendaciones para la prevención, diagnóstico y tratamiento de Amenaza de parto pretérmino, Atención de parto pretérmino espontáneo y Rotura prematura de membranas. Buenos Aires: Dirección Nacional de Maternidad e Infancia, Ministerio de Salud; 2015.

11. Cobo T, Ferrero S, Migliorelli F, et al. Protocolo de Rotura prematura de membranas de término y pretérmino. Barcelona:Centre de Medicina Fetali Neonatal deBarcelona. 2016. [Accessedon: December 5th, 2017]. Available at: https: / / medicinafetalbarcelona.org/clinica/images / protocolos/patologia_materna_obstetrica/rotura\% 20 prematura $\% 20$ de $\% 20$ membranas $\% 20$ hcp-hsjd.pdf.

12. Kenyon S, Boulvain M, Neilson JP. Antibiotics for pre- 
term rupture of membranes. Cochrane Database Syst Rev 2010;(8):CD001058.

13. Ramasethu J, Kawakita T. Antibiotic stewardship in perinatal and neonatal care. Semin Fetal Neonatal Med 2017;22(5):278-83.

14. Otaño L, Meller CH, Aiello H. Avances en terapia fetal. Arch Argent Pediatr 2013; 111(4):332-44.

15. Royal College of Obstetricians and Gynaecologists Antenatal corticosteroids to reduce neonatal morbidity and mortality. Green-Top Guideline. 2010;7. [Accessed on: December 5th, 2017]. Available at: https://pdfs. semanticscholar.org/1983/84fe2a5441444bfc1b7204c4c6 7b827ba0df.pdf.

16. American College of Obstetricians and Gynecologists; Committee on Practice Bulletins-Obstetrics. ACOGPractice Bulletin No. 127: Management of preterm labor. Obstet Gynecol 2012; 119(6):1308-17.

17. Alda E, Apás Pérez de Nucci A, Corimayo L, et al. Recomendaciones para el manejo del embarazo y el recién nacido en los límites de la viabilidad. Buenos Aires: Dirección Nacional de Maternidad e Infancia, Ministerio de Salud; 2013. [Accessed on: December 5th, 2017]. Available at: http:/ / www.msal.gov.ar/images/stories / bes / graficos / $0000000513 \mathrm{cnt-viabilidad.pdf.}$

18. Brownfoot FC, Gagliardi DI, Bain E, et al. Different corticosteroids and regimens for accelerating fetal lung maturation for women at risk of preterm birth. Cochrane Database Syst Rev 2013; (8):CD006764.

19. Roberts D, Brown J, Medley N, et al. Antenatal corticosteroids for accelerating fetal lung maturation for women at risk of preterm birth. Cochrane Database Syst Rev 2017;(3):CD004454.

20. Wapner RJ, Gyamfi-Bannerman C, Thom EA. What we have learned about antenatal corticosteroid regimens. Semin Perinatol 2016;40(5)291-7.

21. Crowther CA, Haslam RR, Hiller JE, et al. Neonatal respiratory distress syndrome after repeat exposure to antenatal corticosteroids: a randomised controlled trial. Lancet 2006; 367(9526):1913-9.

22. Crowther CA, Doyle LW, Haslam RR, et al. Outcomes at 2 years of age after repeat doses of antenatal corticosteroids. N Engl J Med 2007; 357(12):1179-89.

23. Wapner RJ, Sorokin Y, Thom EA, et al. Single versus weekly courses of antenatal corticoisteroids: evaluation of safety and efficacy. Am J Obstet Gynecol 2006;195(3):633-42.

24. Wapner RJ, Sorokin Y, Mele L, et al. Long term outcomes after repeat doses of antenatal corticosteroids. $N$ Engl J Med 2007; 357(12):1190-8.

25. Murphy KE, Hannah ME, William AR, et al. Multiple courses of antenatal corticosteroids for preterm birth (MACS): a randomised controlled trial. Lancet 2008; 372(9656):2143-51.

26. Asztalos EV, Murphy KE, Hannah ME, et al. Multiple courses of antenatal corticosteroids for preterm birth study: 2-year outcomes. Pediatrics 2010;126(5):e1045-55.

27. Asztalos EV, Murphy KE, Willian AR, et al. Multiple courses of antenatal corticosteroids for preterm birth study: outcomes in children at 5 years of age (MACS-5). JAMA Pediatr 2013; 167(12):1102-10.

28. Crowther CA,McKinlay CJ, Middleton P, etal. Repeat doses of prenatal corticosteroids for women at risk of preterm birth por improving neonatal health outcomes. Cochrane Database Syst Rev 2015; (7):CD003935.

29. Crowther CA, Aghajafari F, Askie LM, et al. Repeat prenatal corticosteroid prior to preterm birth: a systematic review and individual participant data meta-analysis for the PRECISE study group (prenatal repeat corticosteroid international IPD study group: assessing the effects using the bestlevel of evidence)-study protocol. Syst Rev 2012;1:12.

30. Committee on Obstetric Pediatrice. Committe Opinion No. 713: Antenatal corticosteroid therapy for fetal maturation. Obstet Gynecol 2017; 130(2):e102-9.

31. South Australian Perinatal Practice Guidelines Workgroup. Preterm Labour Clinical Guideline. 2015. [Accessed on: December 5th, 2017]. Available at: http: / / www.sahealth.sa.gov.au/wps/wcm/ connect/ a75eba804eed9843b021b36a7ac0d6e4/Preterm+Labour Sept2015.pdf?MOD=AJPERES\&CACHEID $=$ ROOTWOR KSPACE-a75eba804eed9843b021b36a7ac0d6e4-lztdxsW.

32. Carlo WA, McDonald SA, Fanaroff AA, et al. Association of antenatal corticosteroids with mortality and neurodevelopmental outcomes among infants born at 22 to 25 weeks' gestation. JAMA 2011; 306(21):2348-58.

33. American College of Obstetricians and Gynecologists, Society for Maternal-Fetal Medicine. ACOG Practice Bulletin No. 144: Multifetal gestations: twin, triplet, and higher-order multifetal pregnancies. Obstet Gynecol 2014;123(4):1118-32.

34. Gyamfi-Bannerman C, Thom EA, Blackwell SC, et al. Antenatal Betamethasone for Women at Risk for Late Preterm Delivery. N Engl J Med 2016; 374(14):1311-20.

35. CheongJL, Doyle LE, BurnettAC, etal. Association Between Moderate and Late Preterm Birth and Neurodevelopment and Social-Emotional Development at Age 2 Year. JAMA Pediatr 2017; 171(4):e164805.

36. Smith GC, RowitchD, MolBW. The role of prenatal steroids at 34-36 weeks of gestation. Arch Dis Child Fetal Neonatal Ed 2017;102(4):F284-5.

37. Doyle LW, Crowther CA, Middleton P, et al. Magnesium sulphate for women at risk of preterm birth for neuroprotection of the fetus. Cochrane Database Syst Rev 2009:(1):CD004661.

38. AMICABLE Group. Antenatal magnesium individual participant data international collaboration: assessing the benefits for babies using the best level of evidence (AMICABLE). Syst Rev 2012; 1:21.

39. Crowther CA, HillerJE, Doyle LW, et al. Effect of magnesium sulfate given for neuroprotection before preterm birth-a randomized controlled trial. JAMA 2003; 290(20):2669-76.

40. Doyle LW, Anderson PJ, Haslam R, et al. Schoolage outcomes of very preterm infants after antenatal treatment with magnesium sulfate vs placebo. JAMA 2014; 312(11):1105-13.

41. Chollat C, Enser M, Houivet E, et al. Schoolage outcomes following a randomized controlled trial of magnesium sulfate for neuroprotection of preterm infants. J Pediatr 2014;165(2):398-400.e3.

42. Marret S, Bénichou J. Antenatal magnesium sulfate and outcomes for school-aged children. JAMA 2015;313(3):306.

43. Meller C, Izbizky G, Otaño L. Actulización sobre el uso de sulfato de magnesio como neuroprotector en el parto prematuro. Arch Argent Pediatr 2015; 113(4):345-51.

44. Lorthe E, Goffinet F, Marret S, et al. Tocolysis after preterm premature rupture of membranes and neonatal outcome: a propensity-score analysis. Am J Obstet Gynecol 2017; 217(2):212.e1-12.

45. Canavan TP, Simhan HN, Caritis S. An evidence based approach to the evaluation and treatment of premature rupture of membranes: Part II. Obstet Gynecol Surv 2004; 59(9):678-89.

46. Mackeen AD, Seibel-Seamon J, Grimes-Dennis J, et al. Tocolytics for preterm premature rupture of membranes. Cochrane Database Syst Rev 2011; (5):CD007062.

47. Vigil-De Gracia A, Savransky R, Pérez Wuff JA, et al. Ruptura prematura de membranas GC. FLASOG 2011;(1). 48. Bond DM, Middleton P, Levett KM, et al. Planned early 
birth versus expectant management for women with preterm prelabour rupture of membranes prior to 37 weeks' gestation for improving pregnancy outcome. Cochrane Database Syst Rev 2017;3:CD004735.

49. Yeast JD. Preterm premature rupture of the membranes before viability. Clin Perinatol 2001; 28(4):849-60.

50. Kiver V, Boos V, Thomas A, et al. Perinatal outcomes after previable preterm premature rupture of membranes before 24 weeks of gestation. J Perinat Med 2017. [Epub ahead of print].

51. Society for Maternal-Fetal Medicine (SMFM) Publications Committee. The choice of progestogen for the prevention of preterm birth in women with singleton pregnancy and prior preterm birth. Am J Obstet Gynecol 2017; 216(3):B11-3.

52. Iams JD. Clinical practice. Prevention of preterm parturition. N Engl J Med 2014; 370(3):254-61.

53. Klinger G, Levy I, Sirota L, et al. Outcome of Early-Onset Sepsis in a National Cohort of Very Low Birth Weight Infants. Pediatrics 2010; 125(4):e736-40.

54. Glasgow TS, Young PC, Wallinn J, et al. Association of intrapartum antibiotic exposure and late-onset serious bacterial infectionsininfants. Pediatrics 2005;116(3):696-702.

55. Diaz Heijtz R. Fetal, neonatal, and infant microbiome: Perturbations and subsequent effects on brain. Semin Fetal Neonatal Med 2016; 21(6):410-7.

56. Ting JY, Synnes A, Roberts A, et al. Association between antibiotic use and neonatal mortality and morbidities in very low-birth-weight infants without culture-proven sepsis or necrotizing enterocolitis. JAMA Pediatr 2016; 170(12):1181-7.

57. Marlow N, Bower H, Jones D, et al. The ORACLE Children Study: educational outcomes at 11 years of age following antenatal prescription of erythromycin or co-amoxiclav. Arch Dis Child Fetal Neonatal Ed 2017; 102(2):F131-5.

58. Korpela K, Salonen A, Virta LJ, et al. Association of early-life antibiotic use and protective effects of breastfeeding role of the intestinal microbiota. JAMA Pediatr 2016; 170(8):750-7.

59. Taylor JA, Opel DJ. Choriophobia: a 1-act play. Pediatrics 2012; 130(2):342-6.

60. Jackson GL, Rawiki P, Sendelbach D, et al. Hospital course and short-term outcomes of term and late preterm neonates following exposure to prolonged rupture of membranes and / or chorioamnionitis. Pediatr Infect Dis J 2012; 31(1):89-90.

61. Jan AI, Ramanathan R, Cayabyab RG.Chorioamnionitis and Management of Asymptomatic Infants $\geq 35$ Weeks Without Empiric Antibiotics. Pediatrics 2017; 140(1):e20162744.

61. Stoll BJ, Hansen NI, Adams-Chapman I, et al. Neurodevelopmental and Growth Impairment Among Extremely Low-Birth-Weight Infants With Neonatal Infection. JAMA 2004; 292(19):2357-65.

62. Cantey JB, Baird SD. Ending the Culture of CultureNegative Sepsis in the Neonatal ICU. Pediatrics 2017; 140(4):e20170044.

63. Rand KM, Austin NC, Inder TE, et al. Neonatal infection and later neurodevelopmental risk in the very preterm infant. J Pediatr 2016; 170:97-104.

64. CarrD, BarnesEH, Gordon A, etal. Effect of antibiotic use on antimicrobial antibiotic resistance and late-onset neonatal infections over 25 years in an Australian tertiary neonatal unit. Arch Dis Child Fetal Neonatal Ed 2017; 102(3):F244-50.

65. Kronman MP, Gerber JS, Prasad PA, et al. Variation in antibiotic use for children hospitalized with inflammatory bowel disease exacerbation: Amulticenter validation study. J Pediatric Infect Dis Soc 2012; 1(4):306-13.

66 Kronman MP,Zaoutis TE,HaynesK, etal.Antibioticexposure and IBD development among children: a population-based cohort study. Pediatrics 2012; 130(4):e794-803.

67. Ungaro R, Bernstein CN, Gearry R, et al. Antibiotics associated with increased risk of new-onset Crohn's disease but not ulcerative colitis: a meta-analysis. Am J Gastroenterol 2014; 109(11):1728-38.

68. Olén O, Askling J, Sachs MC, et al. Childhood onset inflammatory bowel disease and risk of cancer: a Swedish nationwide cohort study 1964-2014. BMJ 2017; 358:j3951.

69. De Cristófano A Uso adecuado de antibióticos en neonatología. Editorial Médica Panamericana. PRONEO, ciclo 11, Módulo 4, 2011.Págs.11-36.

70. Ceriani Cernadas JM. Los perjuicios a corto y largo plazo de la inadecuada indicación de antibióticos en la infancia y adolescencia. Arch Argent Pediatr 2017;115(4):306-7. 